\title{
Synthesis and evaluation of NLO properties of $\pi$-conjugated donor-acceptor systems bearing pyrrole and thiophene heterocycles
}

\author{
M. Cidália R. Castro ${ }^{\mathrm{a}}$, A. Maurício C. Fonseca ${ }^{\mathrm{a}}$, M. Belsley ${ }^{\mathrm{b}}$, M. Manuela M. Raposo*a \\ ${ }^{a}$ Center of Chemistry, University of Minho, Campus of Gualtar, 4710-057 Braga, Portugal \\ ${ }^{\mathrm{b}}$ Center of Physics, University of Minho, Campus of Gualtar, 4710-057 Braga, Portugal
}

\begin{abstract}
Two series of novel push-pull heterocyclic azo dyes have been synthesized and characterized. The two series of compounds were based on different combinations of $\pi$-conjugated bridges (bithiophene and thienylpyrrole) which also act simultaneously as donor groups, together with diazo(benzo)thiazolyl as acceptor moieties. Their thermal stability and electrochemical behavior were characterized, while hyper-Rayleigh scattering (HRS) was employed to evaluate their second-order nonlinear optical properties. The results of these studies have been critically analyzed together with several thienylpyrrole azo dyes reported earlier from our laboratories in which the thienylpyrrole system was used as the donor group functionalized with aryl and (benzo)thiazolyldiazene as acceptor moiety. The measured molecular first hyperpolarizabilities and the observed linear optical and redox behavior showed strong variations in function of the heterocyclic spacers used (bithiophene or thienylpyrrole) and were also sensitive to the acceptor strength of the diazenehetero(aryl) moiety.
\end{abstract}

Keywords: nonlinear optics (NLO), hyper-Rayleigh scattering (HRS) technique, heterocyclic azo dyes, redox potentials, thermal stability, pyrrole, thiophene, (benzo)thiazole.

\section{INTRODUCTION}

Heterocyclic azo dyes are a versatile class of colored compounds that have attracted the interest of many research groups as they have many industrial applications in the fields of textiles, papers, leather, laser materials xerography, laser printing, materials for organic solar cells and chemosensors. In addition, other heterocyclic azo dyes have found recent uses as organic second order nonlinear optical materials (NLO) suitable for applications such as harmonic generation and optical switching. ${ }^{1-2}$ Previous theoretical ${ }^{1}$ and experimental studies ${ }^{2}$ have stimulated a strong intense interest in our research group to engage in the synthesis and characterization of novel heterocyclic azo dyes bearing thiophene, pyrrole and (benzo)thiazole heterocycles. The optical and electronic characterization of several novel chromophores previously synthesized by us confirmed that they possess the essential characteristics necessary for use as efficient solvatochromic probes, nonlinear optical and photochromic materials, ${ }^{3-4}$ supporting the main conclusions of the theoretical studies carried out by Åstrand et al. ${ }^{1}$ In view of these facts and following our recent studies of the synthesis and characterization of heterocyclic azo dyes for optical applications, we considered it worthwhile to synthesize bithiophene and thienylpyrrole derivatives functionalized with thiazolyl and benzothiazolyldiazene moieties and evaluate their electrochemical, thermal and optical (linear and nonlinear) properties.

\section{EXPERIMENTAL TECHNIQUE OF HYPER-RAYLEIGH SCATTERING}

\subsection{Measurement}

Hyper-Rayleigh scattering was used to measure the first hyperpolarizability $\beta$ of response of the molecules studied. The experimental set-up for hyper-Rayleigh measurements is similar to the one presented by Clays et al. ${ }^{5-6}$ Particular care was taken to avoid common pitfalls with this method that can lead to erroneous values for the hyperpolarizability. The incident laser beam came from a Q-switched Nd:YAG laser operating at a $10 \mathrm{~Hz}$ repetition rate with approximately 10 $\mathrm{mJ}$ of energy per pulse and a pulse duration (FWHM) close to $12 \mathrm{~ns}$ at the fundamental wavelength of $1064 \mathrm{~nm}$. The 
incident power could be varied using a combination of a half wave-plate and Glan polarizer. The incident beam was weakly focused (beam diameter $\sim 0.5 \mathrm{~mm}$ ) into the solution contained in a $5 \mathrm{~cm}$ long cuvette. With this cuvette length we are able to aperture only the central region and thereby avoid detecting second harmonic signal from the cell windows. The hyper- Rayleigh signal was collected at right angles to the incident beam and collimated using a high numerical aperture lens (0.8 N.A.). To detect only light emitted near $532 \mathrm{~nm}$ the signal passed first through an infrared blocking filter then through a narrow band interference filter centred at the second harmonic wavelength before being detected by a photomultiplier (Hamamatsu model H9305-04). The current pulse from the photomultiplier was integrated using a Stanford Research Systems gated box-car integrator (model SR250) with a 25 ns gate centred on the temporal position of the incident laser pulse. The hyper-Rayleigh signal was normalized at each pulse using the second harmonic signal from a $1 \mathrm{~mm}$ quartz plate to compensate for fluctuations in the temporal profile of the laser pulses due to longitudinal mode beating. Dioxane was used as a solvent, and the $\beta$ values were calibrated using a reference solution of $p$-nitroaniline $(p \mathrm{NA})^{7-8}$ also dissolved in dioxane at a concentration of $1 \times 10^{-2} \mathrm{~mol} \mathrm{\textrm {dm } ^ { - 3 }}$ (external reference method). The hyperpolarizability of $p$ NA dissolved in dioxane is known from EFISH measurements carried out at the same fundamental wavelength. The concentrations of the solutions under study were chosen so that the corresponding hyperRayleigh signals fell well within the dynamic range of both the photomultiplier and the box-car integrator. All solutions were filtered ( $0.2 \mu \mathrm{m}$ porosity) to avoid spurious signals from suspended impurities.

\subsection{Calculations}

The small hyper Rayleigh signal that arises from dioxane was taken into account according to the equation 1

$$
I_{2 \omega}=G\left(N_{\text {solvent }}\left\langle\beta_{\text {solvent }}^{2}\right\rangle+N_{\text {solute }}\left\langle\beta_{\text {solute }}^{2}\right\rangle\right) I_{\omega}^{2}
$$

where the factor $\mathrm{G}$ is an instrumental factor that takes into account the detection efficiency (including geometrical factors and linear absorption or scattering of the second harmonic light on its way to the detector) and local field corrections. We took especial care to avoid reporting artificially high hyperpolarizibilities due to a possible contamination of the hyper Rayleigh signal by molecular fluorescence near $532 \mathrm{~nm}$. Measurements were carried out using two different interference filters with different transmission pass bands centred near the second harmonic at $532 \mathrm{~nm}$. The transmission band of the narrower filter (CVI model F1.5-532-4) was $1.66 \mathrm{~nm}$ (full width at half maximum) with a transmission of $47.6 \%$ at the second harmonic, while the corresponding values for the wider filter (CVI model F03-532-4) were 3.31 nm, with a transmission of $63.5 \%$ at the second harmonic. The transmission of each filter at the second harmonic wavelength was carefully determined using a crystalline quartz sample. We assume that any possible fluorescence emitted from the solutions is essentially constant over the transmission of both interference filters. Then by comparing the signals obtained with the two different filters we can determine the relative contributions of the hyper-Rayleigh and possible fluorescence signals. The relevant equations (2 and 3) are:

$$
S_{N B}^{2 \omega}=\left(\frac{S_{N B} A_{W B}-S_{W B} A_{N B}}{T_{N B} A_{W B}-T_{W B} A_{N B}}\right) T_{N B} \quad \text { (2) } \quad \text { and } \quad S_{N B}^{F}=\left(\frac{S_{L B} T_{N B}-S_{N B} T_{L B}}{T_{N B} A_{W B}-T_{W B} A_{N B}}\right) A_{N B}
$$

Here $S_{N B}^{2 \omega}$ is the hyper-Rayleigh scattering contribution to the signal, i.e. the signal that would have been measured using the "narrow" band filter if there were no fluorescence present. The fluorescence contribution to the signal measured using the narrow band interference filter is $S_{N B}^{F}$. The signals $S_{N B}$ and $S_{W B}$ are the actual signals measured (after correction for the solvent contribution) using the "narrow" (CVI model F1.5-532-4) and "wide" (CVI model F03-532-4) band interference filters. The transmissions $T_{N B}$ and $T_{W B}$ are respectively the transmission of the "narrow" and "wide" band interference filters at the second harmonic wavelength (47.6\% and 63.5\%), $A_{N B}$ and $A_{W B}$ represent the area under the respective filter's transmission curve. The respective transmission curves were obtained using a dual-beam spectrophotometer with slits adjusted to give $0.1 \mathrm{~nm}$ resolution. We obtained values of $1.29 \mathrm{~nm}$ and $2.18 \mathrm{~nm}$ for $A_{N B}$ and $A_{W B}$ respectively. These values allow us to confidently characterize the first molecular hyperpolarizabilities even when the multi-photon induced fluorescence leads to a contamination of the measured signal by as much as $60 \%$. After determining the amount of signal due solely to hyper-Rayleigh scattering by applying the above procedure the hyperpolarizability of each compound was estimated using the following expression, 


$$
\beta=\beta_{p N a} \sqrt{\frac{S_{n b}^{2 \omega}}{S_{p N a}^{2 \omega}} \frac{N_{p N a}}{N_{c h r o m}}}
$$

Here $N_{\text {chom }}$ and $N_{\mathrm{pNA}}$ are respectively the molar densities of the chromophore and $p$-nitroaniline solutions. In using this expression we assume, as is typical, that the hyperpolarizability tensor is dominated by a single longitudinal element. This is the case for the reference molecule, $p \mathrm{NA}$ with a value of $\beta_{z z z}=16.9 \times 10^{-30}$ esu as measured using the EFISH technique. $^{5-6}$

\section{RESULTS}

\subsection{Synthesis}

Two series of bithiophene 1-2 and thienylpyrrole 4c and 5a azo dyes were synthesized in fair to good yields (9-61\%) through azo coupling reaction of (benzo)thiazolyldiazonium salts with bithiophene ${ }^{9}$ and thienylpyrrole ${ }^{10}$ precursors, in acetonitrile/acetic acid at $0{ }^{\circ} \mathrm{C}$ (Fig. 1, Table 1). The novel heterocyclic azo dyes consists of several push-pull chromophores based on thiophene and pyrrole heterocycles as $\pi$-spacers and simultaneously as electron donor groups functionalized with thiazolyl- or benzothiazolyldiazene moieties as acceptor groups. The new azo dyes were characterized through the usual spectroscopic techniques. The details of the synthesis and the full characterization of compounds 1-2, 4c and 5a will be described elsewhere. The results of the studies concerning the thermal, redox and optical properties of the new azo dyes 1-2, 4c and 5a will be critically analyzed together with three other related compounds 3a and $\mathbf{4 a - b}$ reported earlier from our laboratories ${ }^{3 \mathrm{~d}}$ in which the thienylpyrrole system was used as the donor group and phenyl (3a) or thiazolyldiazene (4a-b) moieties were used as acceptor moieties.
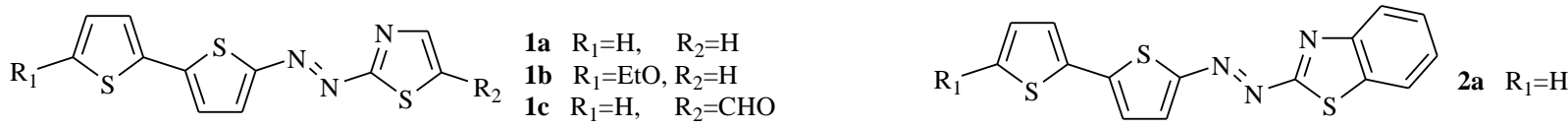<smiles>[R]n1c(/N=N/c2ccccc2)ccc1-c1cccs1</smiles>

3a $\quad \mathrm{R}_{1}=n$-propyl<smiles>[R2]c1cnc(/N=N/c2ccc(-c3cccs3)n2[R])s1</smiles>

4a $\mathrm{R}_{1}=n$-propyl, $\mathrm{R}_{2}=\mathrm{H}$

4b $\mathrm{R}_{1}=4-\mathrm{MeOPh}, \mathrm{R}_{2}=\mathrm{H}$

4c $\mathrm{R}_{1}=4-\mathrm{MeOPh}, \mathrm{R}_{2}=\mathrm{CHO}$

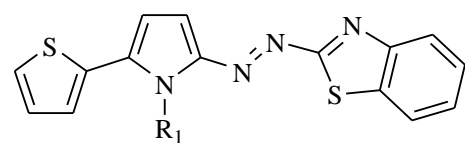

5a $\quad \mathrm{R}_{1}=n$-propyl

Figure 1. Chemical structures of the push-pull chromophores investigated: 1a-c, 2a, 3a, 4a-c and 5a.

Table 1. Yields, IR and $\mathrm{T}_{d}$ data for compounds $\mathbf{1 a - c , ~} \mathbf{2 a}, \mathbf{4} \mathbf{c}$ and $\mathbf{5 a}$.

\begin{tabular}{|cccccc|}
\hline Pyrrole & $\mathrm{R}_{1}$ & $\mathrm{R}_{2}$ & $\begin{array}{c}\text { Yield } \\
(\%)\end{array}$ & $\begin{array}{c}v^{\mathrm{a}} \\
\left(\mathrm{cm}^{-1}\right)\end{array}$ & $\begin{array}{c}\mathrm{T}_{d}{ }^{\mathrm{b}} \\
\left({ }^{\circ} \mathrm{C}\right)\end{array}$ \\
\hline $\mathbf{1 a}$ & $\mathrm{H}$ & $\mathrm{H}$ & 23 & - & 200 \\
$\mathbf{1 b}$ & $\mathrm{EtO}$ & $\mathrm{H}$ & 11 & $2980(\mathrm{~N}=\mathrm{N})$ & 231 \\
$\mathbf{1 c}$ & $\mathrm{H}$ & $\mathrm{CHO}$ & 15 & $1667(\mathrm{C}=\mathrm{O})$ & 231 \\
$\mathbf{2 a}$ & $\mathrm{H}$ & - & 9 & $2925(\mathrm{~N}=\mathrm{N})$ & 283 \\
$\mathbf{4 c}$ & $4-\mathrm{MeOPh}$ & $\mathrm{CHO}$ & 61 & $2933(\mathrm{~N}=\mathrm{N})$ & 200 \\
$\mathbf{5 a}$ & $n$-Propyl & - & 47 & $2919(\mathrm{~N}=\mathrm{N})$ & 239 \\
\hline
\end{tabular}

${ }^{\text {a }}$ The IR spectra were obtained in liquid film $\left(\mathrm{CHCl}_{3}\right) ;{ }^{\mathrm{b}}$ Decomposition temperature $\left(\mathrm{T}_{d}\right)$ measured at a heating rate of $20{ }^{\circ} \mathrm{C}$ min ${ }^{-1}$ under a nitrogen atmosphere, obtained by thermogravimetric analysis (TGA). 


\subsection{Redox properties}

The electrochemical properties of compounds $1-2,4 \mathbf{c}$ and $\mathbf{5 a}$ were analyzed by cyclic voltammetry in DMF solution in the presence of tetrabutylammonium tretrafluoroborate $\left(0.10 \mathrm{~mol} \mathrm{~L}^{-1}\right)$ as supporting electrolyte and the results are listed in the Table 2. All cyclic voltammetric measurements were recorded at room temperature with a conventional three electrode configuration consisting of a vitreous carbon disc working electrode, a platinum wire counter electrode, and a silver-wire pseudo-reference electrode. ${ }^{15 a}$ Cyclic voltametry of compounds 1-2, $\mathbf{4 c}$ and $\mathbf{5 a}$ show an irreversible oxidation process associated with the generation of the cation radical. The data of oxidation potentials show that the extent of the interaction between the electron donating and accepting termini is dependent on the substituent group on the bithiophene and thienylpyrrole spacers and on the thiazole acceptor moiety. Comparing the effect of the electron-donating thienylpyrrole spacer with bithiophene system in the oxidation potentials for compounds 1-2 and $\mathbf{4}$ it can be seen that the electron density in bithienyl-diazenes is lower than that of the thienylpyrrolyl-diazenes, e.g. 1a displays an oxidation at $\mathrm{E}_{\mathrm{pa}}=0.80 \mathrm{~V}$ while $4 \mathbf{a}$ displays an oxidation at $\mathrm{E}_{\mathrm{pa}}=0.59 \mathrm{~V}$. The results also showed that, the energy of HOMO orbital is strongly influenced by the electronic nature of the groups substituted in the thiazole acceptor moiety. Therefore, compounds $\mathbf{1} \mathbf{c}$ and $\mathbf{4} \mathbf{c}$ functionalized with the formyl acceptor group display oxidations at more positive potentials, compared with similar compounds in which $\mathrm{R}_{2}=\mathrm{H}$, as a consequence of the destabilizing effect of the acceptor group on the $\pi$-conjugated systems. All azo dyes bearing a thiazole or benzothiazole acceptor group exhibited two monoelectrolic reductions, on the other hand, compound $3 \mathbf{a}^{3 \mathrm{~d}}$ with phenyldiazene group exhibit only one reduction process. The oneelectron stoichiometry for these reduction processes is ascertained by comparing the current heights with know oneelectron redox processes under identical conditions. ${ }^{11}$ The bithienyl azo dyes show a first process reversible and the second process partially reversible. In the case of thienylpyrrole azo dyes the second redox process is irreversible.

Compounds 1 and 2 showed reversible reduction peaks, with onset potentials between -1.23 and $-0.86 \mathrm{~V}$, which were assigned to the reduction of the thiazolyldiazene moiety. This indicates that the substitution on the bithiophene system with groups of different electronic character have low influence on the reductions potentials, $\left(e . g{ }^{1} \mathrm{E}_{\mathrm{pc}} \mathbf{1 a}=-1.23\right.$ and ${ }^{1} \mathrm{E}_{\mathrm{pc}}$ $\mathbf{1 b}=-1.26 \mathrm{~V})$. On the other hand the reduction potential values are significantly influenced by the substituent on the thiazole moiety, $\left(e . g{ }^{1} \mathrm{E}_{\mathrm{pc}} \mathbf{1 a}=-1.23\right.$ and $\left.{ }^{1} \mathrm{E}_{\mathrm{pc}} \mathbf{1} \mathbf{c}=-0.86 \mathrm{~V}\right)$. The replacement of the bithiophene by the thienylpyrrole spacer shifts the value of the reduction potential of compounds $4 \mathbf{a}-\mathbf{c}^{3 \mathrm{~d}}$ to more negative values (see for example the comparison between $1 \mathrm{a},{ }^{1} \mathrm{E}_{\mathrm{pc}}=-1.23 \mathrm{~V}$ and $4 \mathrm{a}^{3 \mathrm{~d}},{ }^{1} \mathrm{E}_{\mathrm{pc}}=-1.51 \mathrm{~V}$; or between $1 \mathrm{c} ;{ }^{1} \mathrm{E}_{\mathrm{pc}}=-0.86 \mathrm{~V}$ and $\left.4 \mathrm{c} ;{ }^{1} \mathrm{E}_{\mathrm{pc}}=-0.98 \mathrm{~V}\right)$. Therefore, the difference between the reduction potential values obtained for the first process of $\mathbf{4 a}$ and $\mathbf{4 c}$ is $530 \mathrm{mV}$ showing a high anodic shift due to the functionalization of the thiazole ring by a stronger acceptor group. Moreover, the reduction potential of the second process of the reduction reflects also the effect of the electronic nature of the group substituted on the thiazole heterocycle. The substitution of a thiazole heterocycle (4a) by a benzothiazole acceptor group on the diazene system (5a) results in a decrease of the reduction potential for compound $4 \mathbf{a}$ compared to $\mathbf{5 a}$. The electrochemical band gaps of compounds 1-5 were estimated from the difference between the onset potentials for oxidation and reduction and were in the range $1.74-2.51 \mathrm{eV} .{ }^{12-14}$

Table 2. Electrochemical data for compounds 1-5.

\begin{tabular}{|crrrrrr|}
\hline \multirow{2}{*}{ Compound } & \multicolumn{5}{c}{ Reduction $^{\mathrm{a}}$} & Oxidation $^{\mathrm{a}}$ \\
\cline { 2 - 5 } & ${ }^{-1} \mathrm{E}_{\mathrm{pc}}(\mathrm{V})$ & $\Delta \mathrm{E}^{\mathrm{b}}(\mathrm{mV})$ & ${ }^{2} \mathrm{E}_{\mathrm{pc}}(\mathrm{V})$ & $\Delta \mathrm{E}^{\mathrm{b}}(\mathrm{mV})$ & $\mathrm{E}_{\mathrm{pa}}(\mathrm{V})$ & $\begin{array}{c}\text { Band gap } \\
(\mathrm{eV})\end{array}$ \\
\hline $\mathbf{1 a}$ & 1.23 & 63 & 2.04 & 90 & 0.80 & 2.03 \\
$\mathbf{1 b}$ & 1.26 & 62 & 2.07 & 93 & 0.59 & 1.85 \\
$\mathbf{1 c}$ & 0.86 & 63 & 1.61 & 60 & 0.98 & 1.84 \\
$\mathbf{2 a}$ & 1.08 & 54 & 1.93 & 85 & 0.93 & 2.01 \\
$\mathbf{4 c}$ & 0.98 & 65 & 1.69 & - & 0.76 & 1.74 \\
$\mathbf{5 a}$ & 1.36 & 67 & 2.08 & - & 0.70 & 2.06 \\
\hline
\end{tabular}

${ }^{\mathrm{a}}$ Measurements made in dry DMF containing $1.0 \mathrm{mM}$ in each compounds and $0.10 \mathrm{M}\left[\mathrm{NBu}_{4}\right]\left[\mathrm{BF}_{4}\right]$ as base electrolyte at a carbon working electrode with a scan rate of $0.1 \mathrm{Vs}^{-1} . E_{\mathrm{pc}}$ and $E_{\mathrm{pa}}$ correspond to the cathodic and anodic peak potentials, respectively; ${ }^{\mathrm{b}} \Delta \mathrm{E}=$ $\left|\mathrm{E}_{\text {red }}-\mathrm{E}_{\mathrm{ox}}\right| ;{ }^{c} \mathrm{E}_{\mathrm{HOMO}}=-\left(4.39+\mathrm{E}_{\mathrm{ox}}\right)(\mathrm{eV})$ and $\mathrm{E}_{\mathrm{LUMO}}=-\left(\mathrm{E}_{\mathrm{red}}+4.39\right)(\mathrm{eV})$. 
The data showed that several factors have influence on the electronic nature of the $\pi$-conjugated systems leading to the decrease of the band gaps: the type of the electron-donating spacer (bithiophene or thienylpyrrole) and electron-acceptor (thiazole or benzotihiazole) moiety; the strength of the donor group linked to the electron-donating moiety; the strength of the acceptor group linked to thiazole heterocycle.

\subsection{Linear and nonlinear optical properties of the chromophores}

The studied chromophores showed good solubility in common polar and non-polar organic solvents such as dioxane and DMF. The extinction coefficients $(\varepsilon)$ in dioxane and wavelength maxima $\lambda_{\max }$ of compounds $1 \mathbf{a}-\mathbf{c}, \mathbf{2 a}, \mathbf{4 c}$ and $5 \mathbf{a}$ in dioxane were obtained using a Shimadzu UV/2501PC spectrophotometer and are summarized in Table 3. The electronic absorption spectra of the chromophores in dioxane solutions $\left(10^{-4} \mathrm{M}\right)$ showed an intense lowest energy charge-transfer (CT) absorption band in the UV-visible region. The position of this band is strongly influenced by the structure of the compounds, for example by the type of $\pi$-conjugated bridge (bithiophene or thienylpyrrole), by the substitution pattern in the donor and the acceptor moieties and also by the electronic nature of the acceptor moiety. The absorption maxima $\left(\lambda_{\max }\right)$ of azo dyes 1a-c, 2a, $\mathbf{4 c}$ and $\mathbf{5 a}$, in dioxane are located at the range of 477 to $539 \mathrm{~nm}$. As observed earlier for other bithiophene and thienylpyrrole azo dyes, a bathochromic shift in the UV-Vis. spectra is observed when stronger donor and/or acceptor groups are linked to bithiophene or thienylpyrrole heterocyclic systems. ${ }^{3-4,15-16}$
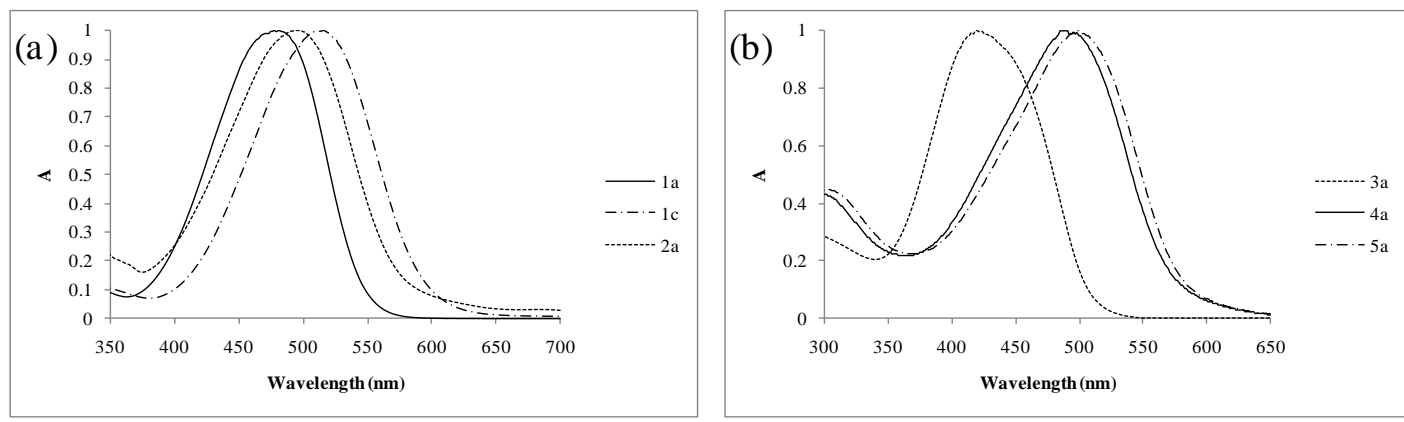

Figure 2.(a) Comparative absorption spectra of 1a, $\mathbf{1 c}$ and $\mathbf{2 a}$ in dioxane at room temperature. (b) Comparative absorption spectra of 3a, $\mathbf{4 a}$ and $\mathbf{5 a}$ in dioxane at room temperature.

As a result the substitution of a $\mathrm{H}$ by the formyl group leads to a red shift of $38 \mathrm{~nm}$ from $477 \mathrm{~nm}(\mathbf{1 a})$ to $515 \mathrm{~nm}(\mathbf{1 c})$. Within the series 1a, 2a and 1c the CT bands moves to lower energy as the electron accepting ability of the acceptor moiety increases, in the order thiazole < benzothiazole < CHO-thiazole (Fig. 2a). A similar effect was observed for the thienylpyrrole derivatives $\mathbf{3 a}, \mathbf{4 a}$ and $\mathbf{5 a}$. Therefore, substitution of an arylazo system $\left(\right.$ e.g. $\left.\mathbf{3 a}^{3 \mathrm{~d}}\right)$ for a thiazolyl azo moiety (e.g. 4a) leads to a red shift of $66 \mathrm{~nm}$ from $420 \mathrm{~nm}$ (e.g. 3a) to $486 \mathrm{~nm}$ for thiazole azo dye $4 \mathbf{a}^{3 \mathrm{~d}}$ On the other hand, substitution of an aryldiazene system by a benzothiazolyl-diazene moiety leads also to a red shift of $80 \mathrm{~nm}$ from $420 \mathrm{~nm}($ e.g. 3a) to $500 \mathrm{~nm}$ due to the increase acceptor ability of the benzothiazole heterocycle compared to phenyl ring and also as a result of a more extensive electron delocalization in $\mathbf{5 a}$ (Fig. 2b). Previous studies have demonstrated that donor-acceptor substituted bithiophene and thienylpyrrole push-pull chromophores exhibit a positive solvatochromism. ${ }^{3-}$ ${ }^{4,15-16}$ In this case a good to large positive solvatochromism was observed moving from diethyl ether to DMSO solutions for bithiophene azo dyes 1a-c $\left(\Delta v_{\max }=1079-1619 \mathrm{~cm}^{-1}\right)$ and for thienylpyrrole diazenes $\mathbf{4 c}$ and $\mathbf{5 a}\left(\Delta v_{\max }=1028-1099\right.$ $\left.\mathrm{cm}^{-1}\right)$.

We have used the hyper-Rayleigh scattering (HRS) method $^{5-6}$ to measure the first hyperpolarizability $\beta$ of compounds 1a-c, 2a, 4a and 5a using the $1064 \mathrm{~nm}$ fundamental wavelength of a laser beam as described above. Dioxane was used as the solvent, and the $\beta$ values were measured against a reference solution of $p$-nitroaniline $(p \mathrm{NA})^{7-8}$ in order to obtain quantitative values, while particular care was taken to properly account for possible fluorescence of the dyes (see experimental section for more details). The static hyperpolarisability $\beta_{0}$ values were calculated using a very simple twolevel model neglecting damping. They are therefore only indicative and should be treated with caution (Table 3 ). 
Table 3. Linear and nonlinear optical properties of chromophores 1a-c, 2a, 3a, 4a-c and 5a. ${ }^{\text {a }}$

\begin{tabular}{|ccccccc|}
\hline Compounds & $\mathrm{R}_{1}$ & $\mathrm{R}_{2}$ & $\begin{array}{c}\lambda_{\max } \\
(\mathrm{nm})\end{array}$ & $\begin{array}{c}\varepsilon_{\max } \\
\left(\mathrm{M}^{-1} \mathrm{~cm}^{-1}\right)\end{array}$ & $\begin{array}{c}\beta^{\mathrm{b}} \\
\left(10^{-30} \mathrm{esu}\right)\end{array}$ & $\begin{array}{c}\beta_{0}^{\mathrm{c}} \\
\left(10^{-30} \mathrm{esu}\right)\end{array}$ \\
\hline $\mathbf{1 a}$ & $\mathrm{H}$ & $\mathrm{H}$ & 477 & 30,240 & 172 & $27 \pm 3$ \\
$\mathbf{1 b}$ & $\mathrm{EtO}$ & $\mathrm{H}$ & 513 & 28,980 & 307 & $16 \pm 1$ \\
$\mathbf{1 c}$ & $\mathrm{H}$ & $\mathrm{CHO}$ & 515 & 30,610 & 286 & $14 \pm 1$ \\
$\mathbf{2 a}$ & $\mathrm{H}$ & - & 493 & 27,990 & 207 & $23 \pm 2$ \\
$\mathbf{4 c}$ & $4-\mathrm{MeOPh}$ & $\mathrm{CHO}$ & 539 & 30,610 & $610^{\mathrm{d}}$ & $12 \pm 1$ \\
$\mathbf{5 a}$ & $n$-Propyl & - & 500 & 35,400 & 590 & 54 \\
$\mathbf{p N A}$ & - & - & 352 & - & $16.9^{7-8}$ & 8.5 \\
\hline
\end{tabular}

${ }^{\text {a }}$ Experimental first hyperpolarizabilities $\beta$ and spectroscopic data measured in dioxane solutions; ${ }^{\mathrm{b}}$ All compounds are transparent at the $1064 \mathrm{~nm}$ fundamental wavelength; ${ }^{\mathrm{c}}$ Data corrected for resonance enhancement at $532 \mathrm{~nm}$ using the two-level model with $\beta_{0}=\beta$ $\left[1-\left(\lambda_{\max } / 1064\right)^{2}\right]\left[1-\left(\lambda_{\max } / 532\right)^{2}\right]$; damping factors not included $1064 \mathrm{~nm} \cdot{ }^{17-19 \mathrm{~d}}$ Value obtained by making measurements at various concentrations and extrapolating to infinite dilution in order to correct for the absorption of the generated second harmonic light as it propagates through the solution to the detection system.

Bithiophene and thienylpyrrole azo dyes 1a-c, 2a, 4a and 5a exhibit good molecular nonlinearities as their $\beta$ values are 10-36 times higher that of the well known $p$ NA molecule for an incident laser wavelength of $1064 \mathrm{~nm}$. From Table 3 it is apparent as well that the increase of the donor strength of the substituent on $5^{\prime}$-position of the bithiophene system (dyes 1a-b) also resulted in a significant resonant enhancement, with enhanced $\beta$ values accompanied by a red-shifted absorption maxima (e.g. 1a, $\mathrm{R}=\mathrm{H}, \lambda_{\max } 477 \mathrm{~nm}, \beta=172 \times 10^{-30} \mathrm{esu} ; \mathbf{1 b}, \mathrm{R}=\mathrm{EtO}, \lambda_{\max } 513 \mathrm{~nm}, \beta=307 \times 10^{-30} \mathrm{esu}$. Noteworthy also the effect of the electronic nature of the group that substitutes the thiazole ring at 5-position. It was observed that, the increase of the acceptor strength of the $\mathrm{CHO}$ group (1c) compared to $\mathrm{H}$ (1a), results both in red-shifted absorption maxima and a resonance enhanced $\beta$ value for bithiophene azo dye 1c $\left(\beta=286 \times 10^{-30}\right.$ esu $)$. A similar effect was observed for thienylpyrrole azo dyes $\mathbf{4 b}$ and $\mathbf{4 c}$. Therefore compound $\mathbf{4 c}$ having a stronger acceptor moiety exhibits a higher $\beta$ value $\left(610 \times 10^{-30} \mathrm{esu}\right)$ for incident light at $1064 \mathrm{~nm}$ as compared to the unsubstituted derivative $4 \mathbf{b}^{3 \mathrm{~d}}\left(156 \times 10^{-30}\right.$ esu). Due to the deficiency of electron density on the ring $\mathrm{C}$ atoms, the thiazole heterocycle acts as electron-withdrawing group and also as an auxiliary acceptor leading to an increase in molecular hyperpolarizability. Comparison of the $\beta$ values for thienylpyrrole azo dye $4 \mathbf{c}$ with bithiophene azo dye 1c showed also that the substitution of a bithiophene spacer by a thienylpyrrole heterocyclic bridge enhances the first order hyperpolarizability from $286 \times 10^{-30}$ to $610 \times 10^{-30}$ esu at $1064 \mathrm{~nm}$ probably due to the stronger auxiliary donor effect of the pyrrole heterocycle compared to the thiophene ring. ${ }^{11,15}$ These results are in agreement with the redox properties described above. Benzothiazole azo dye 5a exhibits a larger $\beta$ value $\left(590 \times 10^{-30}\right)$ compared to the corresponding thiazole chromophore $4 \mathbf{a}^{3 \mathrm{~d}}\left(\beta=164 \times 10^{-30}\right)$ probably due a greater electronic delocalization. Therefore, in the probable resonance structures, the distance between the charges in $\mathbf{5 a}$ being longer compared to $\mathbf{4 a}$, the electric moment of the first diazene must be greater, increasing the value of the molecular hyperpolarizability. A similar behavior was observed for benzothiazole azo dye 2a when compared to their thiazole counterpart 1a.

\subsection{Thermal stability}

For optoelectronic applications, the thermal stability of organic materials is critical for device stability. Therefore, the thermal properties of the chromophores $\mathbf{1 a - c}, \mathbf{2 a}, \mathbf{4 c}$ and $\mathbf{5 a}$ were investigated by thermogravimetric analysis under a nitrogen atmosphere, measured at a heating rate of $20^{\circ} \mathrm{C} \mathrm{min}{ }^{-1}$ ( Table 1). All the chromophores are thermally stable with decomposition temperatures varying from 200 to $283^{\circ} \mathrm{C}$. For the bithienyl-diazenes 1a-c the electronic nature of the group substituted on the 5-position of the thiazole ring does seem to have some impact on the thermal stability of the compounds. The 5-formyl-thiazolyldiazene 1c, is the most stable dye showing the highest decomposition temperature. Benzothiazole azo dye $\mathbf{2 a}$ exhibits also an improved stability by $\mathrm{ca} 83{ }^{\circ} \mathrm{C}$ compared to the corresponding thiazole 
derivative 1a. This property would benefit the practical applications of these chromophores when incorporated into actual optical devices.

\section{SUMMARY}

In this work we report the synthesis, the redox properties and complete physical characterization of novel donor-acceptor chromophores based on pyrrole and thiophene heterocycles. By varying the heterocyclic spacer (bithiophene or thienylpyrrole), the electronic nature of the donor and acceptor groups linked to the bithiophene and thiazole moieties respectively, the thermal and the electrochemical properties as well as the optical (linear and nonlinear) properties of push-pull $\pi$-conjugated systems can be tuned. More interesting redox properties and best first order hyperpolarizabilities were observed for thienylpyrrole azo dyes $\mathbf{4 c}$ and $\mathbf{5 a}$ and bithiophene azo dyes $\mathbf{1 b}$-c, functionalized with a donor ethoxy group in 5'-position of the bithiophene spacer and formyl acceptor group substituted in the 5 position of the thiazole heterocycle. Due to their good first order hyperpolarizability and redox properties together with their good thermal stability these compounds are attractive novel heterocyclic NLO-chromophores.

\section{ACKNOWLEDGEMENTS}

Thanks are due to the Fundação para a Ciência e Tecnologia (Portugal) and FEDER for financial support through the Centro de Química and Centro de Física-Universidade do Minho, Project PTDC/QUI/66251/2006 (FCOMP-01-0124FEDER-007429), Project PTDC/CTM/105597/2008 with funding from COMPETE/FEDER and a research grant to M. C. R. Castro (UMINHO/BI/142/2009). The NMR spectrometer Bruker Avance III 400 is part of the National NMR Network and was purchased within the framework of the National Program for Scientific Re-equipment, contract REDE/1517/RMN/2005 with funds from POCI 2010 (FEDER) and FCT.

\section{REFERENCES}

[1] Åstrand, P. O., Sommer-Larsen, P., Hvilsted, S., Ramanujam, P. S., Bak, K. L. and Sauer, S. P. A., "Fivemembered rings as diazo components in optical data storage devices: an ab initio investigation of the lowest singlet excitation energies," Chem. Phys. Lett., 325, 115-119 (2000).

[2] Towns, A. D., "Developments in azo disperse dyes derived from heterocyclic diazo components," Dyes Pigments, 42, 3-28 (1999).

(b) Yesodha, S. K., Pillai, C. K. S. and Tsutsumi, N., "Stable polymeric materials for nonlinear optics: a review based on azobenzene systems," Prog. Polym. Sci., 29, 45-74 (2004).

[3] (a) Raposo, M. M. M., Sousa, A. M. R. C., Fonseca, A. M. C. and Kirsch, G., "Thienylpyrrole azo dyes: synthesis, solvatochromic and electrochemical properties," Tetrahedron, 61, 8249-8256 (2005).

(b) Raposo, M. M. M., Sousa, A. M. R. C., Fonseca, A. M. C. and Kirsch, G., "Donor-acceptor substituted thienylpyrrole azo dyes: synthesis, solvatochromic and electrochemical properties," Mater. Sci. Forum, 514516, 103-107 (2006).

(c) Coelho, P. J., Carvalho, L. M., Fonseca, A. M. C. and Raposo, M. M. M., "Photochromic properties of thienylpyrrole azo dyes in solution," Tetrahedron Lett., 47, 3711-3714 (2006).

(d) Raposo, M. M. M., Fonseca, A. M. C., Castro, M. C. R., Belsley, M., Cardoso, M. F. S., Carvalho, L. M. and Coelho, P. J., "Novel diazenes bearing pyrrole, thiophene and thiazole heterocycles as efficient photochromic and nonlinear optical (NLO) materials," Dyes Pigments, 91, 62-73 (2011).

[4] (a) Raposo, M. M. M., Ferreira, A. M. F. P., Belsley, M. and Moura, J. C. V. P., Tetrahedron, "5'-Alkoxy-2,2'bithiophene azo dyes: a novel promising series of NLO chromophores," Tetrahedron, 64, 5878-5884 (2008).

(b) Raposo, M. M. M., Ferreira, A. M. F. P., Belsley, M., Matos-Gomes, E. and Moura, J. C. V. P., "5-Arylazo2,2'-bithiophenes: a novel promising serie of NLO chromophores," Mater. Sci. Forum, 587-588, 268-272 (2008).

(c) Raposo, M. M. M., Ferreira, A. M. F. P., Amaro, M., Belsley, M. and Moura, J. C. V. P., "Synthesis and characterization of the thermal and the solvatochromic properties of heterocyclic azo dyes derived from 5-N,Ndialkylamino-2,2’-bithiophene couplers," Dyes Pigments, 83, 59-65 (2009). 
(d) Coelho, P. J., Carvalho, L. M., Moura, J. C. V. P. and Raposo, M. M. M.,"Novel photochromic 2,2'bithiophene azo dyes", Dyes Pigments, 82, 130-133 (2009).

[5] Clays, K. and Persoons, A., "Hiper-Rayleigh scattering in solution," Rev. Sci. Instrum., 63, 3285-3289 (1992).

[6] Clays, K. and Persoons, A., "Hiper-Rayleigh scattering in solution," Phys. Rev. Lett., 66, 2980-2983 (1991).

[7] Teng, C. C. and Garito, A. F., "Dispersion of the nonlinear 2nd-order optical susceptibility of organic-systems," Phys. Rev. B, 28, 6766-6773 (1983).

[8] Stahelin, M., Burland, D. M. and Rice, J. E., "Solvent dependence of the 2nd-order hiperpolarizability in paranitroaniline," Chem. Phys. Lett., 191, 245-250 (1992).

[9] Raposo, M. M. M. and Kirsch, G.,"A combination of Friedel-Crafts and Lawesson reactions to 5-substituted2,2'-bithiophenes," Heterocycles, 55(8), 1487-1498 (2001).

[10] (a) Raposo, M. M. M., Sampaio, A. M. B. A. and Kirsch, G., "Arylamino-thieno-oxobutanamides under Lawesson's conditions: competition between thienylpyrrole and bithiophene formation," Synthesis, 2, 199-210 2005.

(b) Raposo, M. M. M., Sousa, A. M. R. C., Fonseca, A. M. C. and Kirsch, G., "Synthesis of formylthienylpyrroles: versatile building blocks for NLO materials," Tetrahedron, 62(15), 3493-3501 (2006).

[11] Raposo, M. M. M. Sousa, A. M. R. C., Kirsch, G., Cardoso, P., Belsley, M., Matos-Gomes, E. and Fonseca, A. M. C., "Synthesis and characterization of dicyanovinyl-substituted thienylpyrroles as new NLO-chromophores," Org. Lett., 8, 3681-3684 (2006)

[12] Yuan, M.-C., Chiu, M.-Y., Chiang, C.-M. and Wei K.-H., "Synthesis and characterization of pyrido[3,4b]pyrazine-based low-bandgap copolymers for bulk heterojunction solar cells," Macromolecules, 43, 6270-6277 (2010).

[13] Liang, Y., Feng, D., Wu, Y., Tsai, S.-T., Li, G., Ray, C. and Yu, L., "Highly efficient solar cell polymers developed via fine-tuning of structural and electronic properties," J. Am. Chem. Soc., 131, 7792-7799 (2009).

[14] Janietz, S., Bradley, D. D. C., Grell, M., Giebeler, C., Inbaselatan, M. and Woo, E. P., "Electrochemical determination of the ionization potential and electron affinity of poly(9,9-dioctylfluorene)," Appl. Phys. Lett. 73(17), 2453-2455 (1998).

[15] (a) Raposo, M. M. M., Sousa, A. M. R. C., Kirsch, G., Ferreira, F., Belsley, M., Matos Gomes, E. and Fonseca, A. M. C., "Synthesis of tricyanovinyl-substituted thienylpyrroles and characterization of the solvatochromic, electrochemical and non-linear optical properties," Tetrahedron, 61, 11991-11998 (2005).

(b) Raposo, M. M. M., Sousa, A. M. R. C., Fonseca, A. M. C. and Kirsch, G., "Push-pull tricyanovinylsubstituted thienylpyrroles: synthesis, solvatochromic and electrochemical properties," Mater. Sci. Forum, 514516, 98-102 (2006).

(c) Batista, R. M. F., Costa, S. P. G., Malheiro, E. L., Belsley, M. and Raposo, M. M. M., "Synthesis and characterization of new thienylpyrrolyl-benzothiazoles as efficient and thermally stable nonlinear optical chromophores," Tetrahedron, 63(20), 4258-4265 (2007).

(d) Batista, R. M. F., Costa, S. P. G., Belsley, M. and Raposo, M. M. M., "Synthesis and second-order nonlinear optical properties of new chromophores containing benzimidazole, thiophene and pyrrole heterocycles," Tetrahedron, 63(29), 9842-9848 (2007).

[16] (a) Raposo, M. M. M., Fonseca, A. M. C. and Kirsch, G., "Synthesis of donor-acceptor substituted oligothiophenes by Stille coupling", Tetrahedron, 60, 4071-4078 (2004).

(b) Batista, R. M. F., Costa, S. P. G., Lodeiro, C., Belsley, M. and Raposo, M. M.M., "Synthesis and characterization of novel (oligo)thienyl-imidazo-phenanthrolines as versatile $\pi$-conjugated heterocyclic systems for several optical applications," Tetrahedron, 64(39), 9230-9238 (2008).

(c) Herbivo, C., Comel, A., Kirsch, G., Fonseca, A. M. C., Belsley, M. and Raposo, M. M. M., "Synthesis and characterization of novel efficient and thermally stable 2-aryl-5-dicyanovinylthiophenes and 5-aryl-5'dicyanovinyl-2,2'-bithiophenes as potentially promising nonlinear optical (NLO) materials," Dyes Pigments, 82(3), 217-226 (2010).

[17] Oudar, J. L., "Optical nonlinearities of conjugated molecules - stilbene derivatives and highly polar aromatic compounds,” J. Chem. Phys., 67, 446-457 (1977).

[18] Oudar, J. L. and Chemla D. S., "Hiperpolarizabilities of nitroanilines and their relations to excited-state dipolemoment," J. Chem. Phys., 66, 2664-2668 (1977).

[19] Zyss, J. and Oudar, J. L., "Relations between microscopic and macroscopic lowes-order optical nonlinearities of molecular-crystals with one-dimensional or two-dimensional units," Phys. Rev. A, 26, 2016-1027 (1982). 